\author{
Alejandra Castillo \\ Dra. en Filosofía Universidad de Chile. \\ Profesora titular, Departamento de filosofía UMCE \\ alejandrabcastillov@gmail.com
}

\title{
Democracia elitista, universidad y contraescrituras
}

\section{Elitist democracy, university and counterwrites}

\begin{abstract}
Resumen
Este artículo busca describir a la universidad en Chile desde el marco de una democracia elitista y corporativa. Para ello se presentará, primero, la definición de democracia elitista. Segundo, se volverá explícita la relación entre Universidad y la idea de excelencia, palabra clave en las democracias elitistas y corporativas. Y en tercer lugar, se presentarán a las editoriales independientes como máquinas de contra escritura universitaria.
\end{abstract}

Palabras clave: Universidad, democracia elitista, excelencia, editoriales, contra escritura

\begin{abstract}
The purpose of this paper is to describe the university in Chile from the frame of the elitist and corporate democracy. In order to achieve this purpose, firstly we will define the elitist democracy. Secondly, we make explicit the relation between University and the idea of excellence, keyword in elitist and corporate democracys. And thirdly, we present the independent editorials as a university countwrite machine.
\end{abstract}

Keywords: University, elitist democracy, excellence, editorials, countwrite 


\section{Alejandra Castillo}

Toda política implica una política estética, una forma de organización de la representación de lo común. Si esto es así, cabría preguntarse cuál es la forma que ha tomado esta representación de lo común en Chile en los últimos treinta años. Bien podría ser dicho que esta no es otra que la de una democracia elitista (Castillo, 2016). En este punto, me gustaría afirmar que a este encuadre elitista le es afín y complementario un sistema educacional altamente segmentado que no solo genera desigualdad, sino que la presupone.

Revisaré, primero, el encuadre o presupuesto de la democracia elitista. Bajo esta definición, la democracia se comprende como "pluralista". La definición de pluralismo se limita, principalmente, al reconocimiento de diversos intereses enmarcados en las figuras de empresarios y consumidores. La democracia elitista establece los mecanismos necesarios para que los distintos procesos políticos queden en manos de grupos dirigentes que se escogen a sí mismos. El diseño de las democracias elitistas busca el equilibrio entre las partes de antemano involucradas, lo que vuelve difícil el ingreso de sujetos no previstos al juego político. Este modelo de equilibrio es similar al equilibrio entre la oferta y la demanda del mercado, solo que aquí las mercaderías son "políticas”.

Lejos de la retórica de los derechos y de la igualdad con la que habitualmente se asocia la democracia, la democracia elitista es un mecanismo para elegir y autorizar gobiernos. ¿Quiénes participan?: las élites organizadas principalmente en partidos políticos. La democracia elitista es:

"un arreglo institucional para llegar a decisiones políticas - legislativas y administrativas - confiriendo a ciertos individuos el poder de decidir en todos los asuntos, como consecuencia de su éxito en la búsqueda del voto de las personas [...], lejos de ser una forma de vida caracterizada por la promesa de la igualdad y de las mejores condiciones para el desarrollo humano [la democracia elitista] es, sencillamente, el derecho periódico a escoger y autorizar a un gobierno para que actuase en su nombre” (Held, 2007: 206).

La democracia, así entendida, busca en último término legitimar el resultado de las elecciones periódicas entre élites políticas rivales. El equilibrio que genera esta idea de 
democracia es un "equilibrio en la desigualdad", puesto que la supuesta "soberanía del consumidor" es ilusoria. Asumiendo radicalmente esta analogía, se podría decir que si el mercado político es lo bastante competitivo como para producir la oferta y la distribución eficiente de mercaderías políticas (eficiencia en vínculo con la demanda), lo que hace es solo registrar las demandas que pueden tener éxito, es decir, las demandas que cuentan con la capacidad adquisitiva suficiente para ser respaldadas. Ahora bien, en el mercado económico esto significa, sencillamente, dinero. De igual modo, en el mercado político y en el mercado educacional, la capacidad adquisitiva es, en gran medida, sino primordialmente, dinero (Macpherson, 2003: 114).

En sociedades tan desiguales como la nuestra, este modelo solo reproduce desigualdad. Las distintas élites hacen circular entre ellas el prestigio, el poder y los bienes económicos.

Bajo este modelo, la acción política de los individuos queda reducida a la discusión privada y al ejercicio esporádico del voto, y deja el resto a los "expertos", capaces de adoptar las decisiones técnicas de "excelencia" acerca de la organización de los asuntos de lo común. De este modo, bien podría ser dicho que el modelo de sociedad que reproduce la democracia elitista termina por ser antidemocrático.

\section{La idea de excelencia, política y universidad}

Afín a este modelo elitista de la democracia, el sistema educacional chileno, progresivamente, a partir de los años noventa, se comienza a describir, principalmente, como proveedor de mercancías de acuerdo al nivel adquisitivo de diversos "consumidores". Debe advertirse que se mantiene el encuadre republicano heredado de su fundación pública, sin embargo, con una variación: se desplazan los conceptos de "virtud cívica" y "mérito" por el concepto de "excelencia". Una sutil variación, es cierto, pero de importantes consecuencias.

Desde el vocabulario republicano se suele entender la virtud cívica como aquellas “capacidades que los ciudadanos deben poseer para servir al bien público por voluntad propia" (Skinner, 2003: 106). Estas capacidades tienen que ver con el hecho de ser libres y autónomos para participar de la cosa pública sirviendo al bien común como, a su vez, defendiendo la libertad de la comunidad en su conjunto y rechazando la coerción y la dominación. Asimismo, 
la virtud cívica ha sido definida como las relaciones de igualdad entre ciudadanos comprometidos en la doble figura de gobernar y de ser gobernados (Pocock, 2002: 325).

El lenguaje republicano describe la "virtud cívica" como devoción hacia lo público. Esta virtud cívica toma lugar en la participación desinteresada. Es importarte destacar que la idea republicana de virtud cívica se instala en el centro de lo político, desplazando la idea de "fortuna". La discusión contemporánea en torno a lo político ha establecido que la virtud cívica no puede ser entendida como fortuna o como suerte moral - como ha sido actualmente redefinida-, en la medida en que la acción en política virtuosa (republicana) no puede depender únicamente del lugar privilegiado de quien participa en política. Entender la virtud cívica como fortuna o suerte hace caso omiso de las profundas desigualdades existentes en la sociedad en materias de distribución de bienes y riquezas.

Para evitar este calce perverso entre privilegio, política y representación, la política de signo republicano intenta volver posible la "virtud cívica" a través de un sistema educacional de calidad y público. Habría que destacar que solo en ese contexto es posible esgrimir la idea de “mérito". Por el contrario, pensar el mérito sin instituciones republicanas (educación) significa asumir en términos retóricos el léxico republicano de lo político, pero en la práctica avalar una forma de democracia elitista que no cuestiona, sino que más bien presupone la desigualdad de clase y los privilegios de ahí derivados.

El mérito y la virtud cívica nada dicen de "excelencia". La política republicana de los mejores debe ser entendida en el sentido antes mencionado, esto es, la posibilidad de participar en el espacio público sin que esa participación esté motivada por el interés privado ni predeterminada por un orden segregado socioeconómicamente.

Una de las consecuencias de vincular democracia y excelencia es que dicho vínculo tiende a clausurar el debate de lo político, al menos en términos públicos y ciudadanos. Esta clausura se debe principalmente a que la idea de excelencia opera como un significante “apolítico" que pareciera definirse a sí mismo solo con ser enunciado: ¿quién podría oponerse a un gobierno de "excelencia"? Solo con el hecho de enunciar en contigüidad democracia y excelencia se da por sentado que lo propuesto obedece a lo "mejor" y lo más "deseable". De algún modo, cada uno tiene una definición relativamente clara de lo que quiere decir "excelencia", de ahí que no sea necesaria ninguna explicación ni discusión del sentido de la 
palabra. Al respecto, correctamente se ha dicho que la idea de excelencia es parte de aquellos conceptos que parecen estar lejanos de cualquier "ideología", en tanto no tienen un referente externo definido ni un contenido interno unívoco (Readings, 2009: 83).

¿De dónde arranca, entonces, esta vinculación entre política y excelencia? Desde hace algún tiempo se viene advirtiendo de la transformación del léxico de la democracia. Junto al uso más bien nominal de las palabras igualdad, libertad y autonomía se han venido imponiendo con fuerza las de gestión, calidad y excelencia. Tres palabras, entre otras, que cruzan desde el mundo empresarial al mundo de la política y de este al de la educación.

Es relevante destacar que esta transformación del léxico de lo político ocurre de forma paralela tanto en el espacio de la política como en el espacio de la educación superior. En el importante texto The University in Ruins, Bill Readings afirma que la universidad contemporánea es más bien una "corporación burocrática" cuya palabra maestra es la "excelencia" (Readings, 2009). Esta redefinición de la universidad implica, primero, reconocer que la universidad es una empresa y sus estudiantes clientes; segundo, aceptar que al evaluar a las universidades utilizando el recurso de la excelencia se fija un criterio que evoca "algo más", un "calificador cuyo significado se fija en relación a otra cosa", distinta al propio contexto universitario (Readings, 2009: 83). Por último, la idea de excelencia es afín a la exclusión: invocar la idea de excelencia presupone, en términos a priori, un grupo cerrado.

¿Qué efectos tiene para la educación chilena que esta sea definida bajo los signos de la "excelencia"? El traspaso del léxico empresarial de la excelencia al campo de la educación comenzó por definir, lenta pero progresivamente, a esta última en términos corporativos. La principal y perversa consecuencia de la introducción de la excelencia corporativa a nuestro sistema educacional es la segmentación de clases en el seno del propio aparato escolar.

Debe destacarse que el sistema universitario ha definido la idea de excelencia, en primer lugar, como fiscalización y certificación continua. En segundo lugar, en la adopción por parte de la Comisión Nacional de Investigación Científica y Tecnológica (Conicyt) —ahora Agencia Nacional de Investigación y Desarrollo de Chile (ANID) - de un modelo de producción de conocimiento utilitarista, basado en la eficiencia y la cuantificación. Por un lado, la fiscalización ha tomado la forma de la acreditación, que busca principalmente certificar si una institución universitaria es confiable o no al momento de recibir financiamiento público. La búsqueda de 
confiabilidad tiende a estandarizar estructuras, funcionamientos y programas. La acreditación (con sus agencias acreditadoras que, sin duda, son un lucrativo negocio) no es más que una forma de asegurar el capital, no la calidad de la educación. ¿Alguna universidad se arriesgaría a transformar estructuras, funcionamientos y programas por fuera del marco de lo establecido por la acreditación? Por otro lado, la idea de excelencia termina por clausurar todo debate en torno a la triada Estado-universidad-conocimiento.

No habría que perder de vista que la adopción de un modelo de producción de conocimiento basado en la eficiencia y la cuantificación, como el que alienta el sistema de acreditación, termina por debilitar el vínculo entre el espacio universitario y la sociedad civil. Este debilitamiento se da por dos razones. La primera está asociada al sistema de controles externos e internos a los que son sometidas las universidades. Estos controles hacen de la administración el centro de la vida universitaria. Esta forma de control sobre las universidades y la manera en que es concebido en él el rol de la docencia determina que las competencias sitúen a los y las docentes en un plano técnico, es decir, "los descalifican profesionalmente, al traducir en formas transparentes - medibles, cuantificables y acumulables - las habilidades profesionales" (Angulo y Rendón, 2011: 13).

Si tuviera que indicar algunas de las consecuencias que trae consigo la adopción de este modelo de acreditación universitaria, enumeraría las siguientes: primero, genera una tecnocracia pedagógica que termina estableciendo los marcos evaluativos de la docencia y de la investigación según criterios objetivos y cuantificables. En este orden de cuantificación, no habría que dejar de preguntarse cuál es el lugar de las humanidades en este diseño neoliberal de la universidad. Segundo, el estamento docente padece de sobrecarga de trabajo administrativo. Y tercero, el modelo de la acreditación continua debilita la autonomía de los centros universitarios.

Otra causa de desconexión de la universidad con lo público político reside en el propio sistema de investigación nacional promovido por ANID. Se trata de un sistema que privilegia la circulación de conocimientos en redes de revistas indexadas tipo WoS. En este punto, la universidad chilena se vincula claramente al capitalismo de plataformas. Como ya ha sido establecido, esta forma de entender la producción y circulación de conocimiento termina por dar control a las grandes corporaciones sobre los temas que se investigan y las formas en las que se formulan los resultados de la investigación. 
Bien se podría afirmar que esta forma de entender la producción de conocimiento es afín al neoliberalismo y sanciona negativamente cualquier otra alternativa de generación de conocimiento por fuera de las universidades y del circuito de las revistas estandarizadas. No hay que olvidar que bajo la lógica de la puntuación establecida por ANID, no solo cada "producto académico" tiene un valor, sino que también se incorpora la lógica especulativa de hacer responsable al propio "consumidor o académico" de reconocer cuál "producto" es más lucrativo para cada concurso de investigación.

\section{Máquinas de contraescritura}

El neoliberalismo avanza tomando espacios: la política, el sistema escolar y la universidad. Expresado así, se podría pensar que el neoliberalismo es una entidad definida, limitable a un objeto. Quizás como una máquina maligna que en su avance nos va arrebatando, uno a uno, los lugares que percibíamos lejanos de la lógica del lucro y la especulación. Esta imagen de la máquina tiene una ventaja: nos da la posibilidad de situarnos a distancia, como simples espectadoras de una catástrofe que no iniciamos y que no podemos detener porque no tenemos ni la fuerza ni los medios suficientes. Sin embargo, la imagen es falsa. La máquina neoliberal aprendió a tomar para sí acciones mínimas, se abastece del espacio de lo cotidiano. El avance de esta máquina necesita de nuestras pequeñas, no premeditadas - y mecánicasacciones. No tenemos ningún interés en hacer más grande esta máquina y, sin embargo, ahí estamos jugando a favor del neoliberalismo, haciendo lo necesario para que tome otros espacios.

Tenemos clara conciencia de que la universidad ya está tomada. Todo lo que ocurre en el espacio de la universidad ha sido apropiado por los criterios de la certificación, la cuantificación y la indexación. No creo que haya sido distinto antes. La universidad siempre ha estado tomada por las prácticas y procedimientos de la racionalidad hegemónica. Habría que recordar, en este punto, que la universidad es el aparato ideológico del orden dominante. La universidad es la máquina que escribe dicho orden. No habría que abrigar esperanzas allí. O sí, tal vez, quizás una, solo una: esperar que los sentidos comunes que la universidad reproduce se vean tan profundamente alterados por otras máquinas de contraescrituras que terminen por hacerla reproducir otros sentidos, hablas y corporalidades. 
Esas otras máquinas de contraescritura son las editoriales independientes, autónomas, artesanales, cartoneras. Sus nombres son diversos, su nominación no es lo importante, sino lo que hacen. En tiempos en los que la pregunta de Lenin sobre ¿qué hacer? casi no tiene respuesta, que las editoriales independientes desarrollen su porfiada labor de inscripción es ya un gran mérito, aun cuando su "hacer" no responda, en ningún sentido, a un proyecto en conjunto ni a objetivos compartidos ni a búsquedas de resultados en común. Aunque las editoriales independientes se constituyan en diferencia de las lógicas de las militancias políticas, abren un espacio público, dan lugar a otro orden de representación y publicidad.

Estas pequeñas máquinas de contraescritura plantean su quehacer, precisamente, en los márgenes del cuaderno universitario. Estas máquinas intervienen la escritura de la universidad volviendo explícitos sus silencios y exclusiones con ensayos monstruosos que exceden cualquier recorte disciplinar, con traducciones inesperadas, con reediciones que, con su simple vuelta a la actualidad, complejizan el tiempo presente, su política y su corporalidad.

El político profesional desestimaría, sin duda, el poder de estas máquinas de contraescritura por su déficit estratégico o por su falta de articulación. El militante de movimientos sociales las desestimaría por "ilustradas" y, por ello, desconectadas de la "verdad" del pueblo.

A pesar de estos cortocircuitos con la política tradicional, las máquinas de contraescritura no se detienen y avanzan, de manera inadvertida, tramando complicidades, redes, encuentros, amistades y generosidades ¿Acaso las máquinas de contraescritura no han sido otra cosa que amistad?

¿Es posible catalogar, enlistar, acreditar o, derechamente, indexar estas máquinas de contraescritura? Sé que el neoliberalismo avanza tomando espacios nuevos con el objeto de colonizarlos con su lenguaje y procedimientos. Las editoriales independientes se han mantenido al margen de la lógica de la "excelencia" y de la "calidad" que promueven la universidad y los sistemas de acreditación nacional de ciencia y tecnología. Es parte de su política mantenerse al margen. Sin embargo, en el último tiempo se han venido desarrollado diversos proyectos cuyo objetivo es el establecimiento de criterios de medición de la calidad de las editoriales (prestigio, especialización, evaluación ciega, etcétera). Uno de aquellos proyectos es SPI, Scholarly Publishers in Humanities and Social Sciences, desarrollado por el Consejo Superior de 
Investigaciones Científicas (CSIC) de España. Su objetivo declarado, por extraño que resulte, es volver a dar relevancia al "libro", caído en desgracia por el paper. Sin cuestionar la lógica de la cuantificación de los sistemas de acreditación universitarios actuales, SPI extiende esta lógica acrediticia al espacio de la producción editorial. También la plataforma de indexación Scopus ha abierto la posibilidad de indexación de editoriales a pedido de los "propios editores". El neoliberalismo avanza tomando espacios. La imposición no es su consigna, sino el sometimiento voluntario.

Parte de este trabajo de indexación de editoriales ha sido realizado de manera espontánea, y sin ninguna necesidad, por las editoriales universitarias (públicas y privadas) que han venido abultando sus libros con páginas llenas de listas de nombres en direcciones editoriales, comités consultivos, evaluadores expertos, “como si” fueran revistas indexadas.

¿Las editoriales independientes se deberían oponer a esta extensión de la lógica de la cuantificación e indexación? Y, de hacerlo, ¿cuál sería el motivo? ¿Por qué resistir a esta lógica de enlistamiento? ¿Acaso el acceso a fondos públicos, la búsqueda de prestigio académico, la excelencia, la publicidad y la transparencia en los procesos de selección y publicación de manuscritos no son bienes que se deben cautelar? ¿Por qué no contribuir con nuestros esfuerzos a la puntuación de productividad de escritoras y escritores?

Asumir los criterios de cuantificación e indexación por parte de las máquinas de contraescritura sería olvidar la crítica, la creación, la experimentación e incluso el propio deseo de transformación del capitalismo neoliberal. Dicho de otro modo, no habría ningún margen a la máquina de la universidad neoliberal, todo trabajaría para ella, para su particular régimen de comunicación y circulación. Sabemos que el neoliberalismo funciona con dinero y una de sus funciones es la estratificación. ¿Qué les ocurriría a las editoriales independientes si asumieran las reglas de la acreditación y la excelencia? No serían más que otra zona ganada por el capitalismo neoliberal.

Para terminar, retomo el inicio de este texto: toda política implica una estética que visibiliza sujetos, funciones y tiempos. Nuestra política estética se enmarca en una democracia elitista instituida en Chile con la Constitución de 1980, puesta en marcha por expertas/os de los gobiernos de la ex Concertación y vuelta explícita en todos sus matices en los gobiernos dirigidos por la derecha política. Si la democracia elitista ha generado una sociedad cada vez más injusta y 
Alejandra Castillo

una educación de clases, es necesario cambiar el marco: la Constitución de 1980. Hoy es el momento preciso para hacerlo.

\section{Bibliografía:}

Angulo, F. y Rendón, S. (2011). Competencias y contenidos: cada uno en su sitio en la formación docente. En José Carlos Bermejo, La maquinación y el privilegio. El gobierno de las universidades. Madrid: Akal.

Castillo, A. (2016). Disensos feministas. Santiago: Editorial Palinodia.

Held, D. (2007). Modelos de la democracia. Madrid: Alianza.

Macpherson, C. B. (2003). La democracia liberal y su época. Madrid: Alianza.

Pocock, J. G. A. (2002). Virtudes, derechos y manners. En Historia e ilustración. Madrid: Marcial Pons.

Readings, B. (2009). La idea de excelencia, Papel Máquina. Revista de Cultura, año 1, №2, Santiago.

Skinner, Q. (2003). Las paradojas de la libertad política. En Félix Ovejero et al., Nuevas ideas republicanas. Buenos Aires: Paidós. 